\title{
Evaluation of nocturnal bronchoconstriction by all night tracheal sound monitoring
}

\author{
Christine Lenclud, Giuseppina Cuttitta, Daniel Van Gansbeke, Alfredo Visconti, \\ Alain Van Muylem, Vincenzo Bellia, Jean-Claude Yernault
}

\begin{abstract}
Background - A study was undertaken to evaluate the reliability of a digital tracheal sound analyser (ELENS-DSA) in predicting nocturnal changes in airways resistance in asthmatic patients. This device allows continuous measurement of the proportion of the time occupied by wheezing $(\mathrm{Wh} \%)$.
\end{abstract}

Methods - Nocturnal polygraphic studies with simultaneous continuous monitoring of tracheal sounds and airways resistance were performed in seven patients with nocturnal asthma. In order to evaluate the possible bias in wheezing estimation, each tracheal sound recording was passed through the automatic analyser and simultaneously monitored with earphones by an experienced observer.

Results - The device detected audible wheezing with an optimal sensitivity and specificity of $70 \%$. Snoring was a minor cause of the relatively poor characteristics of the system. A close correlation $(p<0 \cdot 001)$ between $\mathrm{Wh} \%$ and airways resistance was observed only in those patients with the highest increase in resistance; when the results of all the subjects were pooled the correlation observed was poor. The predictive value of $\mathrm{Wh} \%$ in detecting changes in airways resistance during 10 minute intervals was lower than $70 \%$. The positive and negative predictive values of $\mathrm{Wh} \%$ were raised to $79 \%$ and $83 \%$, respectively, for 30 minute intervals.

Conclusions - The ELENS-DSA system is a relatively crude means of detecting wheezing and assessing bronchoconstriction quantitatively. However, it is able to detect accurately nocturnal bronchoconstriction for $\mathbf{3 0}$ minute intervals. This finding, along with the fact that the monitoring is non-invasive, suggests that it may be a promising tool, especially for patients during sleep.

(Thorax 1996;51:694-698)

Keywords: nocturnal asthma, wheezing, airways resistance.

Università di Palermo, Italy

Correspondence to: Professor J-C Yernault, Erasmus Hospital Route de Lennik 808 B1070 Brussels, Belgium.

Received 7 November 1994 Returned to authors 24 April 1995

Revised version received 18 December 1995

Accepted for publication

25 January 1996 breathlessness are commonly accepted integral components of asthma ${ }^{1}$; in particu up to $75 \%$ of asthmatic subjects complain of nocturnal attacks. ${ }^{2}$ To assess the effects of treatment, quantification of these symptoms has been attempted by asking the patients to report the number of nocturnal awakenings with wheezing ${ }^{3-5}$ or to attribute a score for morning wheezing. ${ }^{6}$ Other investigators ${ }^{7}$ have evaluated the duration of the wheezing episodes as assessed by auscultation. The symptom score evaluated during the night or upon awakening has been shown to correlate with the overnight change in peak expiratory flow (PEF) ${ }^{8}$ a classical marker of nocturnal asthma. ${ }^{9}$ However, other data suggest that symptoms reported by patients may well underestimate the severity of the nocturnal attacks, since well documented episodes of bronchoconstriction do not necessarily result in arousal. ${ }^{1011}$ In view of these uncertainties, the question arises as to whether objective methods for assessment could be used instead of subjective evaluation, given also that in asthmatic subjects with mild to moderate airways obstruction wheezing is more frequently auscultated than perceived by the patient. ${ }^{1213}$ Two methods have been proposed to measure nocturnal wheezing: continuous recording of respiratory sounds ${ }^{14}$ or repeated auscultation every 30 minutes by experienced nurses. ${ }^{15}$ The latter method is not ideal since episodes of audible nocturnal wheezing may be shorter than 30 minutes. ${ }^{16}$ The former method has become more attractive with the recent advances in signal acquisition and processing which make it possible to recognise and quantify wheezing in sleeping asthmatic subjects. ${ }^{17} 18$ Based on preliminary work by Lens et $a l^{19}$ a digital tracheal sound analyser has been developed (ELENS-DSA, BEA, Liège, Belgium). This device allows continuous measurement of the proportion of the time occupied by wheezing (Wheezing\% or Wh\%) over a whole night. The aim of the present work was to evaluate the reliability of the digital tracheal sound analyser in predicting nocturnal changes in airways resistance in asthmatic patients. In order to evaluate the possible bias in wheezing estimation we also compared the performance of the equipment with continuous monitoring of tracheal sounds by a trained observer.

\section{Methods}

SUBJECTS

Seven adult asthmatic patients fulfilling the ACCP-ATS criteria for the diagnosis of asthma ${ }^{20}$ volunteered to sleep one night in the sleep laboratory for simultaneous monitoring of tracheal sounds and airways resistance. Their main anthropometric and functional characteristics are presented in table 1 . All patients reported frequent episodes of nocturnal awakenings because of dyspnoea and wheezing and showed a recurrence of morning dips of peak expiratory flow - that is, a fall in the early 
Table 1 Anthropometric and pulmonary function data for the seven asthmatic patients recorded in the morning preceding the night of the study

\begin{tabular}{llllllll}
\hline Patient & Sex & Age & Smoking & $F E V_{1}($ ) & $F E V_{1}$ (\% pred) & $F E V_{1} / V C$ & Asthma severity \\
\hline $\mathrm{Ni}$ & $\mathrm{F}$ & 50 & No & $2 \cdot 75$ & 68 & 67 & Moderate \\
$\mathrm{Ga}$ & $\mathrm{M}$ & 35 & No & $2 \cdot 73$ & 75 & 64 & Moderate \\
$\mathrm{Sp}$ & $\mathrm{M}$ & 37 & No & $2 \cdot 23$ & 69 & 51 & Moderate \\
$\mathrm{Il}$ & $\mathrm{M}$ & 26 & No & $3 \cdot 91$ & 93 & 78 & Moderate \\
$\mathrm{Ia}$ & $\mathrm{F}$ & 54 & No & 1.91 & 65 & 58 & Moderate \\
$\mathrm{Pi}$ & $\mathrm{M}$ & 36 & Ex & $1 \cdot 53$ & 37 & 71 & Severe \\
$\mathrm{Lo}$ & $\mathrm{M}$ & 24 & Yes & $3 \cdot 40$ & 88 & Moderate \\
\hline
\end{tabular}

$\mathrm{FEV}_{1}=$ forced expiratory volume in one second; $\mathrm{VC}=$ vital capacity.

morning value at least equal to $20 \%$ of the maximum daily value - over the preceding two weeks. They showed reversible airways obstruction and required associated treatment for optimal control of symptoms. They had not suffered from recent deterioration of their symptoms so that the usual medications could be withdrawn 12 hours before the study in all but one patient $(\mathrm{Pi})$. No subject was obese or a heavy snorer. The study was approved by the appropriate ethical committee of the University of Palermo. Informed consent was obtained from the subjects prior to the study.

PROTOCOL

The tracheal sounds were recorded by an electret microphone (sensitivity $10 \mathrm{mV} / \mathrm{Pa}$; frequency $50-20000 \mathrm{~Hz}$; linearity $\pm 2.5 \mathrm{~dB}$ from 50 to $20000 \mathrm{~Hz}$ ) fixed by wide adhesive tape (OpSite) at the level of the suprasternal notch, $1-2 \mathrm{~cm}$ above the upper margin of the sternum. The microphone was connected to a long term tape recorder (UHER CR 1600; speed 0.47 in/s; band width $60-3400 \mathrm{~Hz}$ ) using the two sound tracks in the auto-reverse mode for an eight hour recording. Recordings were later simultaneously listened to and passed through the sound analyser. The signal was amplified (gain $60 \mathrm{~dB}$ ) and filtered by a band pass $200-1000 \mathrm{~Hz}$ filter with an attenuation rate of $48 \mathrm{~dB} /$ oct. The filtered sound signal was then digitised at $2048 \mathrm{~Hz}$ samples per second and each 250 ms segment was submitted to spectral analysis using a Fast Fourier Transform (FFT). The analyser detected for each 250 ms segment the peak with the highest amplitude (Amax), its corresponding frequency $\left(\mathrm{F}_{0}\right)$, and the mean amplitude of the whole signal (Amean). A narrow peak in the power spectrum with an Amax/ Amean ratio of $>30$ was systematically considered as a wheeze by the system. In addition, peaks with an Amax/Amean ratio of 10-30 might also be considered as a wheeze according to an algorithm for which the patent is currently pending. Results of 120 consecutive $250 \mathrm{~ms}$ samples were subsequently grouped into a 30 second period and Wh\% was calculated by dividing the number of $250 \mathrm{~ms}$ samples containing wheezes by the total number of $250 \mathrm{~ms}$ samples over the period. The software automatically displayed the Wh\% every 30 seconds and was able to display the $\mathrm{Wh} \%$ for every segment of the night, as well as for the whole night.

In addition to the above parameters, electroencephalographic, electro-oculographic, and chin electromyographic data were recorded as for standard sleep staging. ${ }^{21}$ Oronasal flow (V) was measured by a light tight fitting face mask (approximately $80 \mathrm{ml}$ dead space) sealed to the face with denture adhesive, with a pneumotachograph (Fleisch no. 1) connected to a differential pressure transducer (model MP45 , range $\pm 5 \mathrm{~cm} \mathrm{H}_{2} \mathrm{O}$, Validyne, Northridge, California, USA). A perforated tube, positioned adjacent to the skin on the outside edge of the face mask, was connected to a mass spectrometer (model MGA 200, Centronic Ltd, UK) to detect any air leak between the mask and the face. The resistance of the mask/ pneumotachograph system was $1.4 \mathrm{~cm} \mathrm{H}_{2} \mathrm{O} / \mathrm{l}$.s measured at a $\dot{V}$ of $200 \mathrm{ml} / \mathrm{s}$. Transpulmonary pressure (PTP) was measured by a balloon tipped catheter placed in the lower third of the oesophagus and connected to a calibrated differential pressure transducer (model MP45 , range $\pm 80 \mathrm{~cm} \mathrm{H}_{2} \mathrm{O}$, Validyne) referenced to the mask. The length of tubing placed on the reference side of the manometer and connected to the mask was adjusted to balance the opposite sides of the transducer. The balance was checked in a closed chamber by application of sine wave pressures up to a frequency of $6 \mathrm{~Hz}^{22}$ The position of the oesophageal catheter was adjusted according to the occlusion technique proposed by Baydur et al. ${ }^{23}$

All signals were recorded on an eight channel strip chart recorder (model 7758B, HewlettPackard, Waltham, Massachusetts, USA) and on an eight channel magnetic tape recorder (model 3968A, Hewlett-Packard) for further playback and analysis. $\dot{V}$ and PTP signals were sampled at $10 \mathrm{~ms}$ intervals and, after analogue to digital conversion, were stored in the mass memory of a computer (Vax 8200, Digital Equipment, Maynard, Massachusetts, USA). From the calibrated $\dot{V}$ and PTP signals, the computer calculated, breath-by-breath, inspiratory ( $\mathrm{Ri}$ ) and expiratory $(\mathrm{Re})$ total pulmonary resistances using the method of Mead and Whittenberger. ${ }^{24}$ On each flow-pressure loop the value for resistance was calculated by a linear regression $(\Delta \mathrm{P}=\mathrm{R} \times \dot{\mathrm{V}}$, where $\mathrm{P}$ is pressure and $R$ is resistance) that takes into account only the points at which $\dot{V}$ was $0-200 \mathrm{ml} / \mathrm{s}$ for inspiration and expiration. The computer calculations were continuously submitted to visual control to avoid the introduction of artifacts. Since episodes of partial occlusion of the pharyngeal airway may occur from time to time due to loss of muscle tone, we limited our analysis to expiratory resistance only, taking also into account the fact that, in a previous study, ${ }^{25}$ a close relationship was found between $\mathrm{Re}$ and $\mathrm{Ri}$ in non-snoring 
Table 2 Mean values relevant to baseline $\overline{(\overline{R e}} b$. expressed in $\left.\mathrm{cm} \mathrm{H}_{2} \mathrm{O} / \mathrm{l} \cdot \mathrm{s}\right)$ and maximal increase in expiratory resistance (Max\% $\overline{R e}$ ) for each asthmatic patient. Correlation coeficient $(r)$ between $\mathrm{Wh} \%$ and mean expiratory resistance $(\mathrm{Re})$ calculated for 10 minute sequences

\begin{tabular}{llll}
\hline Patient & $\overline{R e} b$ & Max\% $\overline{R e}$ & $r$ \\
\hline $\mathrm{Ni}$ & 13 & 327 & $0 \cdot 76^{* * *}$ \\
$\mathrm{Ga}$ & $11 \cdot 2$ & 382 & $0 \cdot 69^{* * *}$ \\
$\mathrm{Sp}$ & 10 & 360 & $0 \cdot 68^{* * *}$ \\
$\mathrm{Il}$ & 20 & 268 & $0 \cdot 42^{* *}$ \\
$\mathrm{Ia}$ & 15 & 270 & $0 \cdot 42^{* *}$ \\
$\mathrm{Pi}$ & 15 & 229 & $0 \cdot 34^{*}$ \\
$\mathrm{Lo}$ & 13 & 208 & $0 \cdot 38$ \\
\hline
\end{tabular}

${ }^{*} \mathrm{p}<0.05 ;{ }^{* *} \mathrm{p}<0.01 ;{ }^{* * *} \mathrm{p}<0.001$.

patients as well as in the snore-free breaths of snorers. $\operatorname{Re}$ recording values were averaged over 10 minute sequences $(\overline{\mathrm{Re}})$.

\section{ASSESSMENT OF WH\% SCORE CHARACTERISTICS BY LISTENING}

The sound recordings of the seven patients were simultaneously passed through the automatic analyser and monitored with earphones by an experienced observer who was unaware of the automatic analysis results. Breaks were set after each hour to keep the observer attentive. For each 30 second corresponding period the observer counted the number of adventitious continuous sounds, classifying them as wheezes or as snores. A wheeze was defined as an inspiratory or expiratory low or high pitched musical sound. ${ }^{26}$ A snore was defined as an inspiratory or expiratory raspy "snort-like" sound. The characteristics of the Wh\% score were assessed by the ROC curve technique. ${ }^{27}$ We computed the sensitivity and the specificity of the Wh\% score with cutoff values of $1-10 \%$, a cutoff value being the value behind which the event was considered as positive (otherwise negative). The gold standard in this analysis was the wheeze at listening: at

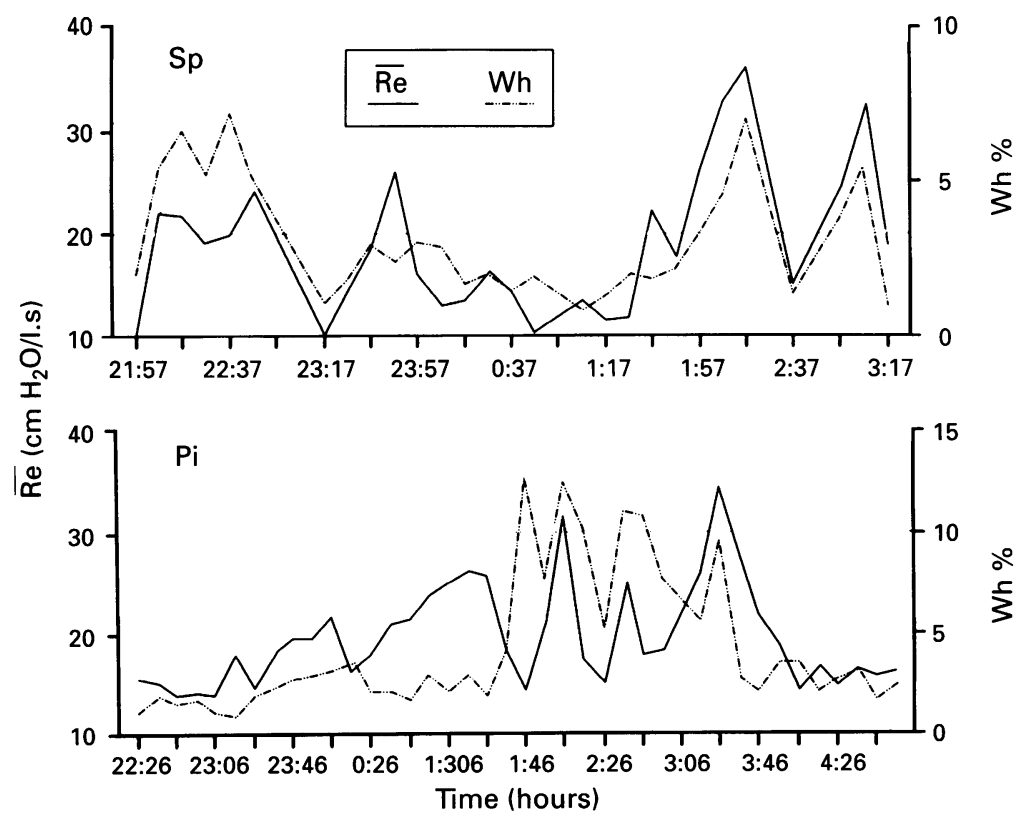

Figure 1 Time course of wheezing \% (Wh\%) and mean expiratory resistance $(\overline{R e})$ over 10 minute sequences in two asthmatic subjects. least one audible wheeze was a positive event and no audible wheeze a negative event. The ROC curve was constructed by considering sensitivity (true positive rate) as a function of ( 1 -specificity) (false positive rate) which we computed for all events (4331 30 second periods) and for those events without snoring (2585 30 second periods).

\section{Results}

Subjects were studied for a mean of 375 minutes (range 215-495). The total sleep time averaged 158 minutes (range 124-226). No rapid eye movement (REM) sleep was recorded in five patients (stages $1-2,84 \%$; stages 3-4, $16 \%)$. The remaining two patients slept through non-REM and REM stages. During the night all patients showed significant increases in pulmonary resistance. Table 2 shows the mean values relevant to baseline - that is, 10 minutes of wakefulness before sleep onset - and the maximal increase in expiratory resistance. We considered as an episode of bronchoconstriction a value of expiratory resistance higher than or equal to $200 \%$ of the baseline value. Episodes of bronchoconstriction occurred only in the second part of the night in two patients ( $\mathrm{Pi}$; fig 1 ) while in the remaining five patients they occurred during the entire night ( $\mathrm{Sp}$; fig 1 ).

\section{ASSESSMENT OF WH\% SCORE CHARACTERISTICS} BY LISTENING

Figure 2 shows the ROC curves for all 30 second periods and for 30 second periods without snoring. The ROC curves may be characterised by their intersection with the second bisector giving the cutoff value at which sensitivity is equal to specificity. These "optimal" values of sensitivity are $0.7(70 \%)$ and $0.72(72 \%)$ for all 30 second periods and 30 second periods without snoring, respectively, and are obtained at a cutoff value of $\mathrm{Wh} \%$ of about $3 \%$.

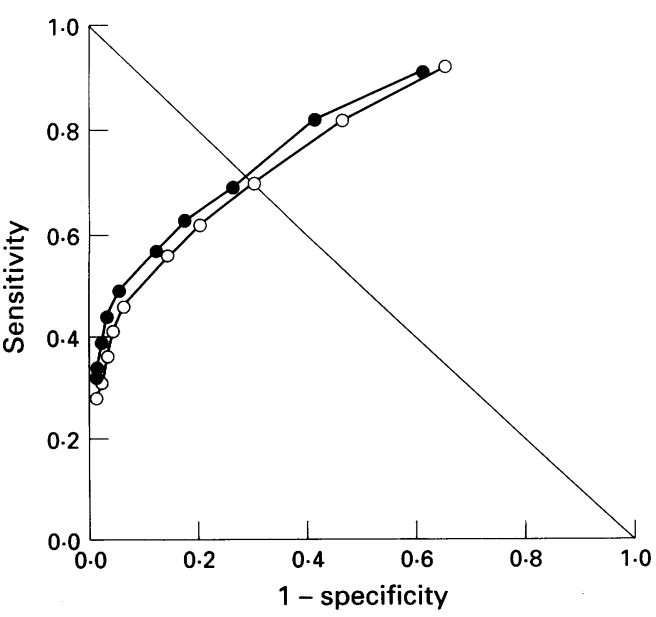

Figure 2 ROC curves for all 30 second events (O) and for 30 second events without snoring (O). Each point on a given curve corresponds to a cutoff value of Wh\% score ranging from $1 \%$ to $10 \%$ from right to left. 

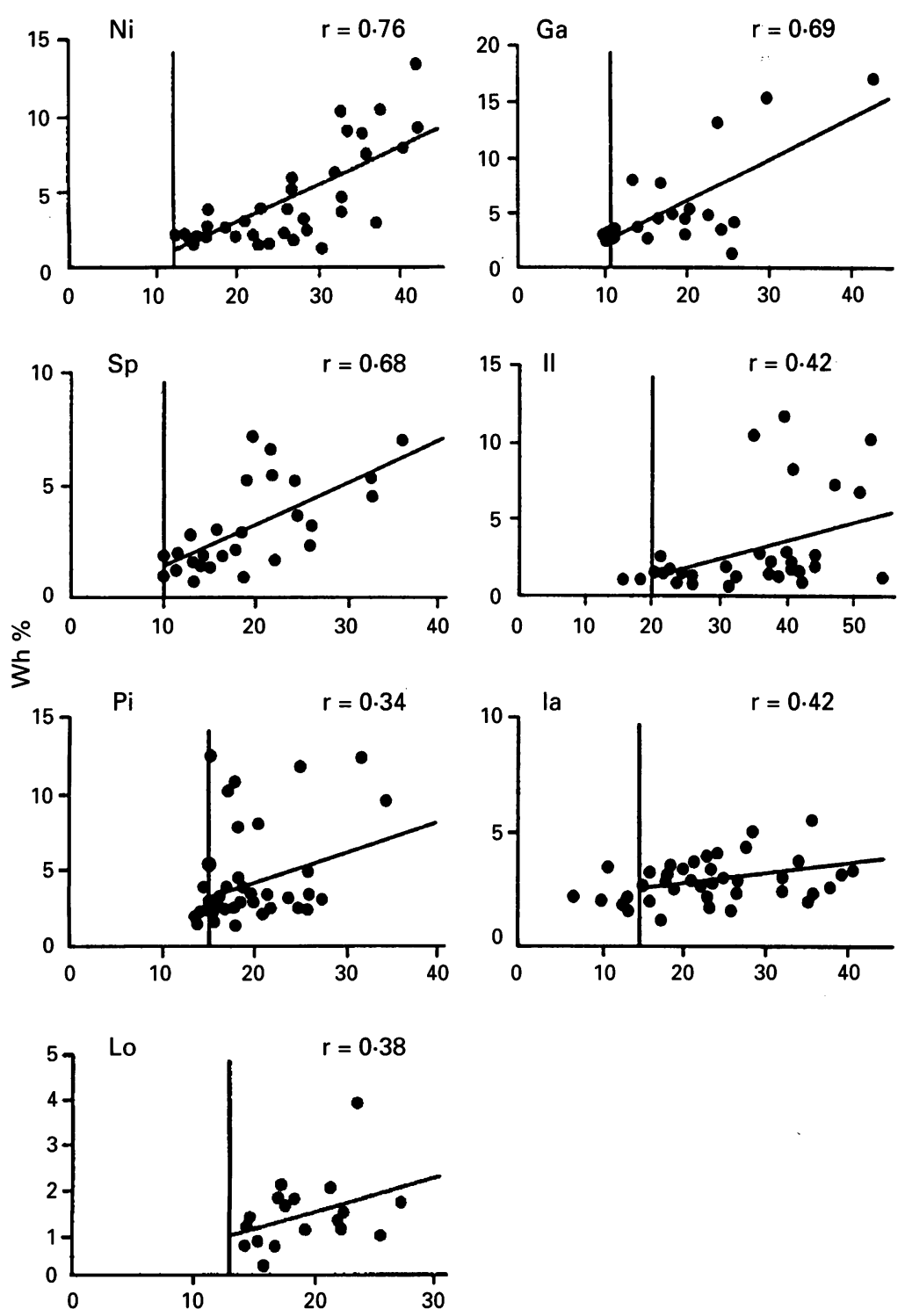

$\overline{\operatorname{Re}}\left(\mathrm{cm} \mathrm{H} \mathrm{H}_{2} \mathrm{O} / \mathrm{s}\right.$ )

Figure 3 Correlation between wheezing \% (Wh\%) and mean expiratory resistance $(\overline{\operatorname{Re}})$ over 10 minute sequences in the seven asthmatic patients. The vertical line indicates the baseline expiratory resistance.
$65 \%$ and $69 \%$, respectively. Using the Bayes theorem ${ }^{28}$ the positive and negative predictive values for a $50 \%$ prior probability of a bronchoconstriction occurring were $66 \%$ and $68 \%$, respectively.

We repeated the above analysis by pooling three 10 minute periods ( 30 minute periods). A true positive event was then defined as a bronchoconstriction event with a Wh\% score of $>3 \%$ within the same half hour, but not necessarily in the same 10 minute period. Under these conditions a sensitivity and specificity equal to $75 \%$ and $85 \%$, respectively, were obtained and positive and negative predictive values of $79 \%$ and $83 \%$, respectively.

\section{Discussion}

In this study the trachea rather than the chest was chosen as the site for recording the respiratory sounds as the trachea offers a more precise localisation of the recording site as well as a higher sound level. ${ }^{29}$ Moreover, the attachment of the microphone did not cause any discomfort to the subjects. Tracheal auscultation has also been recommended in asthmatic subjects because sounds originating in the first airway generations are better transmitted through airways than through the lungs. ${ }^{3031}$

For the evaluation of the performance of the digital sound analyser to detect wheezing we used the monitoring of tracheal sounds by a trained observer as the reference method. This approach has its own limitations since observer agreement for describing respiratory sounds is not perfect. ${ }^{32}$ We adopted the single feasible reference method of simply enumerating the number of wheezes per period of time, as proposed by Hoffstein et $a l^{33}$ for snoring.

The constructed ROC curves (fig 2) showed that the optimal cutoff value of $\mathrm{Wh} \%$ for the device was around 3\%. At this point sensitivity was equal to $70 \%$, and the shape of the curve shows that no improvement in sensitivity can be achieved without a concomitant loss in specificity of the same amount. Comparison between the ROC curve for all events and the ROC curve for the events without snoring showed an improvement in sensitivity and in specificity of only $2 \%$ when the patients did not snore, which shows that snoring is only a minor cause of the relatively poor characteristics of the device which may be caused by the wheeze detection algorithm itself or by some other technical factors. In particular, the filtering of tracheal sounds by a $1000 \mathrm{~Hz}$ low pass filter before analogue to digital conversion at the sampling rate of $2048 \mathrm{~Hz}$ can probably not completely avoid aliasing ${ }^{34}$ (the aliasing artifact is a phenomenon resulting from digitising fewer than two samples per period in a periodic function). Another possible cause might be the presence of a face mask and oesophageal balloon in asthmatic subjects. Nonetheless, this equipment was indispensable for performing continuous functional measurements. This study was conducted in a soundproof sleep laboratory. It is probable that, 
in less favourable conditions, adventitious sounds may also be picked up by the device.

The relationship between wheezing parameters and the degree of bronchoconstriction has been evaluated by several authors for selected short periods ${ }^{12} 133536$ but it has never been studied continuously during sleep. Our study showed that monitoring of both airways resistance and Wh\% show significant fluctuations during the night (fig 1). The Wh\% curve varies with the airways resistance, but a close correlation $(p<0.001)$ was only observed in those patients with the highest increase in resistance, and the correlation observed by pooling all asthmatic subjects was poor. The monitoring of Wh\% cannot therefore be proposed as a quantitative method of measuring nocturnal bronchoconstriction. In the same way, it has a poor predictive value (less than $70 \%$ ) in detecting changes in expiratory resistance over short periods (10 minutes), but over a longer time period ( 30 minutes) the positive and negative predictive values increased to $79 \%$ and $83 \%$, respectively. Thus, for a 30 minute period monitoring of $\mathrm{Wh} \%$ is an acceptable means of detecting bronchoconstriction.

We conclude that the ELENS-DSA system has relatively poor characteristics for detecting wheezing, and it is also a relatively crude means of assessing bronchoconstriction quantitatively. On another hand, the system is able to detect bronchoconstriction accurately during a 30 minute period and this, together with the fact that the monitoring is non-invasive and easy to use, suggests that it may be a promising tool for detecting wheezing, especially for patients during sleep.

This work was supported in part by grant no. 3.4569 .88 from the Fonds de la Recherche Scientifique Médicale.

$\mathrm{C}$ Lenclud was a Fondation Erasme grant holder.

1 Editorial. Cough and wheeze in asthma: are they interdependent? Lancet 1988;i:447-8.

2 Turner-Warwick $M$. The definition and recognition of nocturnal asthma. In: Turner-Warwick M, Levy J, eds. New perspectives of theophylline therapy. London: The Royal Society of Medicine 1984:1-4

3 Stewart IC, Rhind GB, Power JT, Flenley DC, Douglas NJ. Effect of sustained release theophylline on symptoms and sleep quality in patients with nocturnal asthma. Thorax 1987;42:797-800.

4 Heins M, Kurtin L, Oellerich M, Maes R, Sybrecht GW. Nocturnal asthma: slow-release terbutaline versus slow-
release theophylline therapy. Eur Respir $\mathcal{f} 1988 ; 1: 306-10$.

5 Dahl R, Pedersen D, Hägglöf B. Nocturnal asthma: effect of treatment with oral sustained-release terbutaline, inhaled budesonide, and the two in combination. 7 Allengy Clin budesonide, and the two in

6 Helm SG, Meltzer SM. Improved control of asthma in the office setting. Am $\mathcal{F}$ Med 1988;85(Suppl 1B):30-3.
7 Bose B, Cater JI, Clark RA. A once daily theophylline preparation in prevention of nocturnal symptoms in childhood asthma. Eur $\mathcal{F}$ Pediatr 1987;146:524-7.

8 Martin RJ, Cicutto LC, Ballard RD. Factors related to nocturnal worsening of asthma. Am Rev Respir Dis 1990; 141:33-8.

9 Turner-Warwick $M$. On observing patterns of airflow obstruction in chronic asthma. Br fDis Chest 1977;71:73-86.

10 Bellia V, Visconti A, Insalaco G, Cuttitta G, Ferrara G, Bonsignore $G$. Validation of morning dip of peak expiratory flow as an indicator of the severity of nocturnal asthma. Chest 1988;94:108-10.

11 Bellia V, Cuttitta G, Insalaco G, Visconti A, Bonsignore G. Relationship of nocturnal bronchoconstriction to sleep stages. Am Rev Respir Dis 1989;140:363-7.

$12 \mathrm{McF}$ adden ER Jr, Kiser R, Degroot WJ. Acute bronchial asthma. Relations between clinical and physiological manifestations. N Engl F Med 1973;288:221-5.

13 Shim CS, Williams MH Jr. Relationship of wheezing to the severity of obstruction in asthma. Arch Intern Med 1983; 143:890-2.

14 Kales A, Kales JD, Sly RM, Scharf MB, Tan T, Preston TA. Sleep patterns of asthmatic children: all night electroencephalographic studies. F Allergy 1970;46:300-8.

15 Martin ME, Grunstein MM, Larsen GL. The relationship of gastrooesophageal reflux to nocturnal wheezing in children with asthma. Ann Allergy 1982;49:318-22.

16 Issa FG, Sullivan CE. Respiratory muscle activity and thoracoabdominal motion during acute episodes of asthma during sleep. Am Rev Respir Dis 1985;132:999-1004.

17 Baughman RP, Loudon RG. Lung sound analysis for continuous evaluation of airflow obstruction in asthma. Chest 1985;88:364-8.

18 Baughman RP, Loudon RG. The utility of a long-acting sympathicomimetic agent, procaterol, for nocturnal sympathicomimetic agent, pro

19 Lens E, Postiaux G, Chapelle P. Nocturnal asthma monitoring by automated spectral analysis of respiratory sounds. Bull Eur Physiopathol Respir 1987;23(Suppl 12): 423s.

20 ACCP-ATS Joint Committee on Pulmonary Nomenclature. Pulmonary terms and symbols. Chest 1975;67:583-93.

21 Rechtschaffen A, Kales A, eds. A manual of standardized terminology, techniques and scoring system for sleep stages of human subjects. Los Angeles:UCLA Press, 1968.

22 Hudgel DW. Variable site of airway narrowing among obstructive sleep apnea patients. F Appl Physiol 1986;61: 1403-9.

23 Baydur A, Behrakis PK, Zin WA, Jaeger M, Milic-Emili J. A simple method for assessing the validity of the esophageal balloon technique. Am Rev Respir Dis 1982;126:788-91.

24 Mead J, Whittenberger JL. Physical properties of human lungs measured during spontaneous respiration. $\mathcal{f} A p p l$ Physiol 1953;5:790-6.

25 Cibella F, Cuttitta G, Romano S, Grassino A, Bellia V. Ventilatory response to spontaneous resistive load variations during sleep. F Appl Physiol 1994;76:2394-404

26 Waring WW, Beckerman RC, Hopkins RL. Continuous adventitious lung sounds: site and method of production and significance. Semin Respir Med 1985;6:201-9.

27 Lusted LB. Decision-making studies in patient management. $N$ Engl f Med 1971;284:416-24.

28 Taro Yamane. Statistics: an introductory analysis. 3rd edition. New York: Harper and Row, 1973.

29 Charbonneau G, Racineux JL, Sudraud M, Tuchais E. An accurate recording system and its use in breath sounds accurate recording system and its use in breath

30 Loudon R, Murphy RLH Jr. Lung sounds. Am Rev Respir Dis 1984;130:663-73

31 Editorial. Say ninety-nine. Lancet 1986;1258-9.

32 Pasterkamp H, Wielbicke W, Fenton R. Subjective assessment vs computer analysis of wheezing in asthma. Chest 1987;91:376-81.

33 Hoffstein V, Mateika JH, Mateika S. Snoring and sleep architecture. Am Rev Respir Dis 1991;143:92-6.

34 Sanchez I, Powell RE, Pasterkamp H. Wheezing and airflow obstruction during metacholine challenge in children with cystic fibrosis and in normal children. Am Rev Respir Dis 1993;147:705-9.

35 Marini JJ, Pierson DJ, Hudson LD, Lakshminarayan S. The significance of wheezing in chronic airflow obstruction. significance of wheezing in chronic airl
Am Rev Respir Dis 1979;120:1069-72.

36 Baughman RP, Loudon RG. Quantification of wheezing in acute asthma. Chest 1984;86:718-22. 